\title{
Établissement de l’Église catholique au Nouveau-Brunswick
}

\section{Edgar Godin}

Volume 48, 1981

URI : https://id.erudit.org/iderudit/1007099ar

DOI : https://doi.org/10.7202/1007099ar

Aller au sommaire du numéro

Éditeur(s)

Les Éditions Historia Ecclesiæ Catholicæ Canadensis Inc.

ISSN

0318-6172 (imprimé)

1927-7067 (numérique)

Découvrir la revue

Citer cet article

Godin, E. (1981). Établissement de l’Église catholique au Nouveau-Brunswick. Sessions d'étude - Société canadienne d'histoire de l'Église catholique, 48, 37-56. https://doi.org/10.7202/1007099ar

Tous droits réservés @ Les Éditions Historia Ecclesiæ Catholicæ Canadensis Inc., 1981
Ce document est protégé par la loi sur le droit d'auteur. L'utilisation des services d'Érudit (y compris la reproduction) est assujettie à sa politique d'utilisation que vous pouvez consulter en ligne.

https://apropos.erudit.org/fr/usagers/politique-dutilisation/ 


\section{Établissement de l'Église catholique au Nouveau-Brunswick}

En 1981, le Nouveau-Brunswick compte une population d'environ 710,000 personnes. C'est une petite population dans une petite province. Cependant. il est intéressant de noter qu'au moins $52 \%$ de cette population est catholique. Il y a quatre diocèses : Moncton, SaintJean, Bathurst et Edmundston. Cette présentation a pour but d'étudier sommairement l'évolution de l'Église catholique dans cette province, depuis les débuts de la colonisation en 1604 jusqu'à l'érection de son quatrième diocèse en 1944.

\section{AVANT LA CONGRÉGATION DE LA PROPAGANDE 1604-1622}

L'Église catholique exerce sa juridiction spirituelle dans le monde entier. Il y a des parties du monde qui ne sont pas encore érigées en diocèse. Depuis 1622, ces pays de mission ont été placés, par le Pape, sous la juridiction d'une Congrégation romaine, appelée Congrégation de la Propagande. Avant cette date, le Pape déléguait sa juridiction à des communautés religieuses exemptes qui exerçaient le ministère dans les pays de mission.

Lorsque les premiers prêtres catholiques sont arrivés dans le territoire actuel du Nouveau-Brunswick, la Congrégation de la Propagande n'était pas encore fondée. Ces missionnaires devaient obtenir leur juridiction soit du Pape, soit d'un supérieur religieux habilité à le faire. Il appert, malgré quelques opinions divergentes, que les évêques ne pouvaient pas déléguer de juridiction aux prêtres partant de leur diocèse pour les pays de mission.

L'organisation de l'Église catholique au Nouveau-Brunswick s'est effectuée conjointement avec la colonisation du pays par la France. Le 8 septembre 1603, Henri IV nommait le sieur Pierre de Monts, lieutenant général en Acadie, avec la mission apostolique de "convertir les peuples qui habitent en cette contrée". Mais le roi de France ne pouvait pas déléguer de juridiction ecclésiastique aux missionnaires 
qui viendraient en Acadie. De plus, Pierre de Monts était huguenot. Mais pour être fidèle à la maison que lui confiait Henri IV. Pierre de Monts se fit accompagner, lors de son premier voyage en 1604, par deux prêtres catholiques, dont l'un était l'abbé Nicolas Aubry, de Paris.

Ces prêtres avaient-ils obtenu l'autorisation de leurs supérieurs pour exercer du ministère en pays de mission ? Aucun document connu ne le démontre. Quoi qu'il en soit, ils ne semblent pas avoir exercé de ministère au Nouveau-B̈runswick. Cependant, Samuei de Champiain, qui accompagnait de Monts à la rive du Nouveau-Brunswick, en l'absence du prêtre, le 24 juin 1604, a baptisé la rivière Saint-Jean. Il annexait ainsi tout le territoire à l'Église qu'il représentait comme catholique.

Six ans plus tard, la partie sud du Nouveau-Brunswick fut visitée par l'abbé Jessé Fléché, un prêtre du diocèse de Langres, France, venu en Acadie en 1610 avec le sieur de Poutrincourt. Il était muni d'autorisations papales, obtenues par l'entremise du nonce apostolique à Paris. En juin 1610, il fit une courte visite à l'embouchure de la rivière Saint-Jean. Il y avait là une bourgade indienne, et quelques pêcheurs français, avec Robert du Pont. L'abbé Fléché serait le premier prêtre catholique à être venu au Nouveau-Brunswick. Aucune référence documentaire n'indique qu'il y aurait célébré la messe.

Dès 1604, Henri IV avait invité les jésuites à envoyer des missionnaires en Acadie. Mais les supérieurs avaient hésité. En 1608, ils acceptèrent le projet, cependant les missionnaires jésuites ne partirent qu'en 1611. Le Père Pierre Biard et le Père Enémond Massé furent les deux premiers. Le supérieur général des jésuites, en vertu des constitutions de son Ordre, approuvées par Rome, et de privilèges également obtenus de Rome, pouvait envoyer des missionnaires en pays infidèles, et leur accorder les facultés nécessaires. Mais le Père Biard voulait obtenir des facultés encore plus étendues. Le 12 octobre 1610, il demanda au Pape les privilèges extraordinaires accordés aux Indes. En réponse à cette requête, les missionnaires jésuites reçurent certains privilèges concernant le sacrement de pénitence, mais au for interne seulement. Au for externe, ils devaient juger les conditions selon les cas, et ensuite demander les facultés, si nécessaire.

Le Père Biard exerça son ministère au Nouveau-Brunswick, mais sa mission fut de courte durée. En octobre 1611, parti de la NouvelleÉcosse, il remonta la rivière Saint-Jean jusqu'à l'Ile aux Garces, actuellement l'Ile Caton, avec le sieur de Biencourt. Il y célébra la 


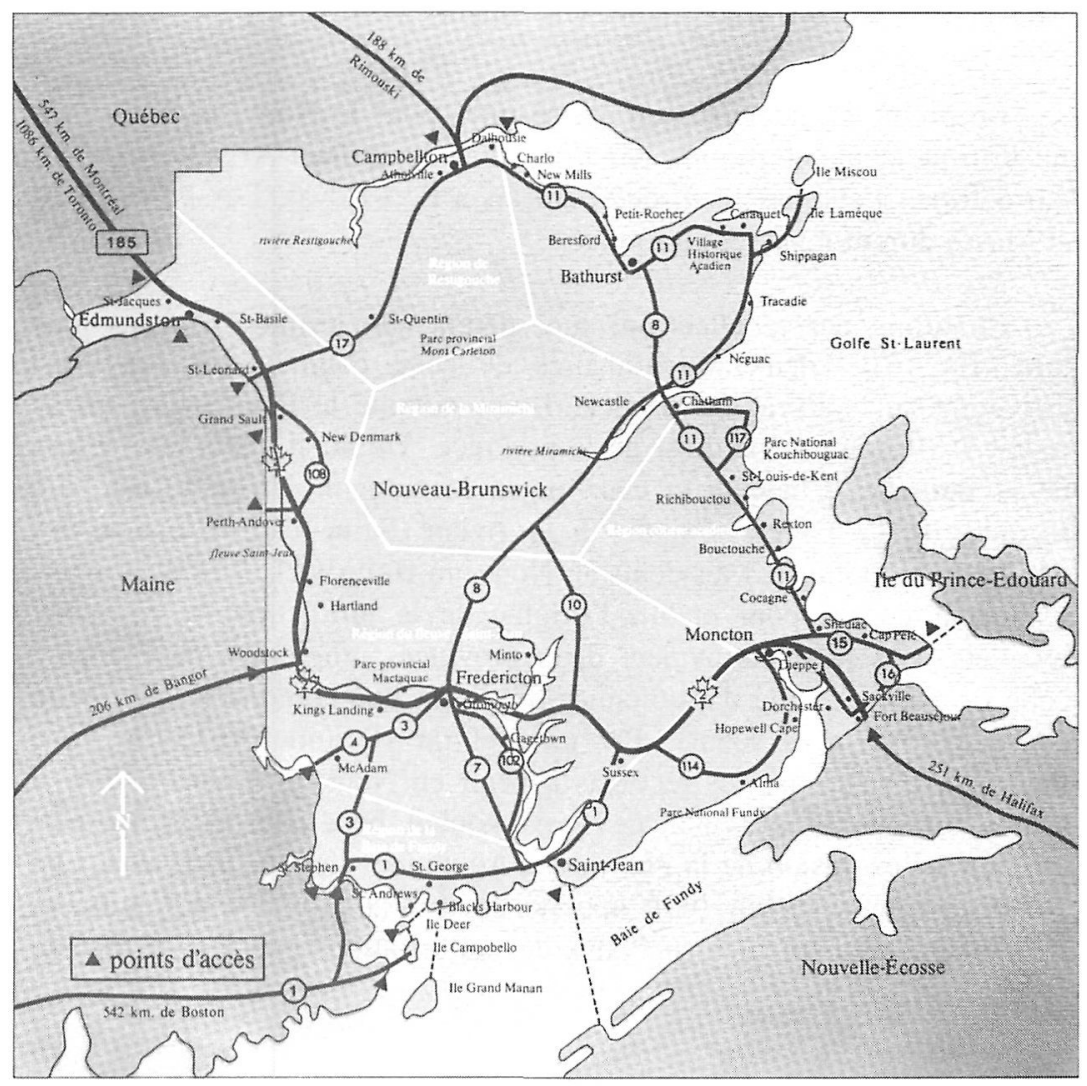

Ci-comere: Rivière Digdeguash: derniere couvernure: plage Parlee 
messe. la première en cette province. Une plaque commémorative rappelle cet événement historique important. Le Père Massé, compagnon du Père Biard, passa l'hiver 1611-1612 avec les Indiens du sud du Nouveau-Brunswick pour étudier leur langue.

Le projet d'évangélisation des jésuites pour le Nouveau-Brunswick fut brusquement interrompu par l'invasion de Samuel Argall, en 1613 , qui détruisit l'établissement des Français à Port-Royal. Les Pẹrẹs Riard et Massé durent repasser en France.

Ce furent des récollets qui succédèrent aux jésuites. six ans plus tard. En 1619, deux missionnaires de cette communauté religieuse arrivèrent au Nouveau-Brunswick. L'un, nommé le Père Sébastien, se rendit à Miscou, au nord-est de la province. De là. il visita les Indiens de la Baie des Chaleurs et ceux de la Miramichi. Un autre, le Père Jacques de la Foyer, s'intalla à la rivière Saint-Jean. C'étaient les premiers missionnaires résidents au Nouveau-Brunswick. Les documents manquent encore pour établir l'origine de la juridiction de ces deux récollets. Les récollets avaient deux provinces religieuses en France : celle de Paris et celle d'Aquitaine. Il existait une certaine rivalité entre ces deux provinces soeurs. Par un bref du 10 juillet 1615, le Pape Paul $\mathbf{V}$ avait autorisé les récollets à venir en Nouvelle-France. Mais il semblerait que la province de Paris voulait bénéficier de cette permission à l'exclusion de la province d'Aquitaine. Les récollets venus au Nouveau-Brunswick en 1619 appartenaient à la province d'Aquitaine. Ils s'étaient probablement prévalus des autorisations papales du bref de 1615 .

\section{SOUS LA CONGRÉGATION DE LA PROPAGANDE 1622-1659}

Le 22 juin 1622, la Congrégation de la Propagande fut fondée, sous l'autorité du Pape, avec juridiction dans tous les pays de mission. Le Nouveau-Brunswick passait ainsi sous l'administration de cette nouvelle Congrégation romaine. À cette époque cependant, les missions de l'Amérique du Nord étaient peu connues à Rome. C'est ce qui pourrait expliquer qu'aucun membre de la Propagande ne fut chargé des missions canadiennes. Ce n'est que trois ans plus tard que cette Congrégation s'intéressa effectivement aux missions du NouveauBrunswick. En 1625, un carme de Londres, le Père Simon Stock, mit la Congrégation au courant des dangers qui menaçaient les catholiques de l'Amérique du Nord, en raison de l'établissement des colonies anglaises et protestantes en ces régions. C'est à partir de cette démarche 
que la Propagande s'intéressa à l'évangélisation du continent nordaméricain.

Les capucins furent les premiers missionnaires envoyés au NouveauBrunswick par la Congrégation de la Propagande. Le grand souci de validité de leur juridiction se manifeste dans les requêtes de leur mandat. Le 22 novembre 1630, la Congrégation de la Propagande avait nommé les Pères Joseph et Léonard, tous deux capucins de Paris, préfets des missions capucines en Nouvelle-Angleterre. En 1632, les capucins décidèrent d'ouvrir une mission en Acadie, de préférence à Québec. Leur mandat de 1630, qui leur accordait juridiction en NouvelleAngleterre, devait être réajusté. Les capucins de Paris demandèrent alors à Rome que le mandat de leurs préfets soit revisé et fait spécifiquement pour la Nouvelle-France. La Propagande approuva la mission des capucins en Nouvelle-France, mais ne changea pas les titres du mandat, destiné aux missions de la Nouvelle-Angleterre. Les autorités de Paris n'étaient pas encore satisfaites de cette délégation implicite. À leur demande, la Propagande étendit les pouvoirs des missions capucines à la Nouvelle-France, le 24 septembre 1632, seize jours après l'arrivée des capucins en Acadie.

Les capucins avaient eu raison de faire expliciter leur mandat par la Propagande. Lorsqu'ils arrivèrent à la rivière Saint-Jean, au sud du Nouveau-Brunswick, ils y trouvèrent une mission dirigée par les récollets. Ceux-ci firent valoir leurs droits sur cette mission. Les capucins se retirèrent en Nouvelle-Écosse et ne revinrent au NouveauBrunswick qu'en 1645 , après le départ des récollets.

Ils établirent une communauté régulière, avec un monastère et une chapelle, à l'embouchure de la rivière Saint-Jean. Ces missionnaires capucins exercèrent un ministère fructueux chez les Français, et également chez les Indiens de la Vallée de Saint-Jean. Ils remontèrent la rivière jusqu'à Woodstock, où se trouvait le principal village indien. Il y en avait environ 2,000 le long de la rivière. Presque tous reçurent le baptême. Les missions étaient difficiles, car les missionnaires devaient étudier la langue indigène et suivre les Indiens dans leurs déplacements saisonniers.

Un grand missionnaire capucin, le Père Balthazar de Paris, se rendit au nord-est du Nouveau-Brunswick, en 1648, et établit sa résidence dans la région de Bathurst. Il y oeuvra pendant six ans.

La mission des capucins se termina tragiquement en 1654. Au mois d'août, le fort Saint-Jean fut détruit par le major Sedgewick du 
Massachusetts. Les capucins se réfugièrent à Port-Royal. Le territoire du Nouveau-Brunswick passa alors au pouvoir anglais.

Les récollets revinrent au Nouveau-Brunswick une deuxième fois, en 1631. Cette deuxième mission provenait encore de la province d'Aquitaine, mais cette fois elle était munie des autorisations requises, accordées par la Congrégation de la Propagande. Ils demeurèrent à la rivière Saint-Jean jusqu' en 1645 .

En 1635, le Père Paul Lejeune, supérieur des jésuites à Québec, envoya deux missionnaires à Miscou, petite île située à l'extrémité nord-est du Nouveau-Brunswick. Un poste militaire y avait été établi par les Français, l'année même. Les jésuites étaient arrivés à Québec en 1632, munis de l'autorisation de leur supérieur, mais sans intervention du Saint-Siège. Selon leurs constitutions, approuvées par Rome avant l'institution de la Congrégation de la Propagande, les supérieurs jésuites pouvaient envoyer des missionnaires en pays de mission. Ces pouvoirs avaient-ils été révoqués par l'institution de la Propagande ? Ce n'est que le 20 février 1648, à la demande du général des jésuites, que Rome leur accorda les facultés requises pour les missions.

En 1642, les jésuites décidèrent de fermer leur mission de Miscou et de s'établir à Bathurst, toujours dans le nord-est de la province. C'était alors un centre de communication facile pour les missionnaires. De Bathurst, ils pouvaient facilement visiter les Indiens de la Miramichi et de Richibouctou au sud, et ceux de la Ristigouche au nord. À Bathurst, alors appelé Nipisiguit, les jésuites construisirent une résidence, une chapelle et une clinique pour les malades. Leur travail auprès des Indiens de la côte est du Nouveau-Brunswick fut très fructueux. Après 1663, il semble bien que les jésuites n'avaient plus de missionnaires résidents au Nouveau-Brunswick.

\section{VICARIAT APOSTOLIQUE - 1659}

En 1659, le Nouveau-Brunswick fut intégré dans le vicariat apostolique de la Nouvelle-France, institué par un décret du 6 mai 1658. Mgr de Laval, vicaire apostolique, arriva à Québec le 17 juin 1659. Comme vicaire apostolique, il n'avait pas de juridiction personnelle. Il recevait sa juridiction directement du Pape. Cette situation juridique allait alors à l'encontre du droit gallican, mais le roi de France approuva la nomination de $\mathrm{M}^{\mathrm{gr}}$ de Laval, et le litige fut réglé.

Les fidèles du Nouveau-Brunswick, - en majorité des indigènes furent parmi les premiers catholiques à bénéficier du ministère épiscopal 
de Mer de Laval. Les missionnaires jésuites de Bathurst et Richibouctou avaient appris que le vicaire apostolique, en arrivant de France, devait faire escale à Gaspé, avant de se rendre à Québec. Ils y conduisirent un groupe considérable de leurs fidèles pour l'accueillir. Il y avait une distance d'environ 150 kilomètres à faire en bateau, de Bathurst à Gaspé. La grande majorité de ces catholiques étaient de nouveaux convertis et voyaient un évêque pour la première fois. Ils eurent le privilège de participer à la première cérémonie de confirmation célébrée par un évêque au Canada.

$M^{\mathrm{gr}}$ de Laval exerça ses fonctions de vicaire apostolique au NouveauBrunswick, depuis sa résidence de Québec, pendant 15 ans. Pendant cette période, les missions au Nouveau-Brunswick avaient subsisté, mais d'une façon assez précaire. Les jésuites, les récollets et les capucins y avaient évangélisé les indigènes, et la grande majorité avait accepté la foi chrétienne. Mais les missionnaires devenaient de plus en plus rares. Les capucins et les récollets avaient quitté le Nouveau-Brunswick. Les jésuites diminuaient graduellement en nombre. Les communautés religieuses ne recevaient plus de sujets de France. C'est ainsi qu'en 1672, il n'y avait plus de missionnaires au Nouveau-Brunswick. Voyant cette triste situation, en 1673, Mgr de Laval confia les missions de cette province aux récollets. Ils revenaient dans un champ d'apostolat déjà connu. Le plus célèbre d'entre eux fut le Père Chrétien Leclercq. Et la même année, $M^{\mathrm{gr}}$ de Laval envoya un prêtre diocésain, l'abbé LouisPierre Thury, dans les missions du Nouveau-Brunswick.

\section{LE NOUVEAU-BRUNSWICK ET LE DIOCÈSE DE QUÉBEC SOUS LE RÉGIME FRANÇAIS}

En 1674, le Nouveau-Brunswick franchit une nouvelle étape dans son histoire ecclésiastique. Le ler octobre de cette année, $\mathbf{M}^{\mathrm{gr}}$ de Laval, jusqu'alors vicaire apostolique de Nouvelle-France, fut nommé évêque du diocèse de Québec. Le Nouveau-Brunswick était compris dans ce nouveau diocèse. Comme évêque de plein droit, $\mathbf{M}^{\text {gr }}$ de Laval ne dépendait plus de la Congrégation de la Propagande, mais directement du Saint-Siège.

Cependant le Nouveau-Brunswick demeurait à l'état missionnaire. Sa population était encore très clairsemée. Les régions de la Baie des Chaleurs et de la Miramichi avaient un certain noyau de population catholique. Mais en 1692, les Français furent chassés de Bathurst par un chef indien malveillant. Quelques missionnaires de passage y exercè- 
rent encore leur ministère auprès des Indiens et de rares familles françaises.

En 1674, il y avait environ 3,000 Indiens à la rivière Saint-Jean. À peu près tous étaient catholiques. Les Français y firent de nouvelles tentatives de colonisation, mais sans trop de succès. Le Père Claude Moreau, récollet, ayant sa résidence en Nouvelle-Écosse, exerçait son ministère à la rivière Saint-Jean, mais le premier prêtre résident dans ce territoire à cette époque fut le Père Simon de la Place. récollet. Les missionnaires se succédèrent à la rivière Saint-Jean jusqu'en 1763. Ils avaient leur résidence habituelle à Medoctec, aujourd'hui Woodstock, mission indienne au nord de Fredericton. Le Père Jean-Baptiste Loyard. s.j., y construisit une église en 1717. Un village français s'était établi à Sainte-Anne, aujourd'hui Fredericton. Une chapelle desservait cette mission, sans prêtre résident, semble-t-il. Un prêtre remplissait les fonctions d'aumônier au Fort Saint-Joseph, en face de Fredericton, vers 1693.

Lorsque le diocèse de Québec fut érigé en 1674, il y avait très peu de catholiques dans le sud du Nouveau-Brunswick. Mais graduellement les Acadiens de la Nouvelle-Écosse vinrent s'installer dans cette région. Vers 1697, des colons de Beaubassin fondèrent le village de Chipoudy, aujourd'hui Hopewell, dans le comté d'Albert. D'autres se rendirent dans la région de Moncton et de Memramcook. Les Indiens étaient installés à Tintamarre, au nord de l'Isthme de Chignectou. Presque chaque village avait une chapelle, et les missionnaires les visitaient occasionnellement.

Les catholiques du Nouveau-Brunswick furent impliqués dans le conflit qui suivit le traité d'Utretch. Par ce traité signé en 1713, la France céda l'Acadie à l'Angleterre. Les Français pour leur part prétendaient que l'Acadie ne comprenait que la Nouvelle-Écosse, alors que les Anglais réclamaient tout le Nouveau-Brunswick. Si le Nouveau-Brunswick devenait territoire anglais, les catholiques perdaient leur liberté religieuse. Le conflit de frontière ne fut jamais réglé. C'était pour affirmer les droits de la France à la rivière Saint-Jean qu'en 1717, le roi de France fit construire une chapelle à Médoctec. Et les catholiques du Nouveau-Brunswick continuèrent à jouir de leur liberté religieuse.

Mais en 1744 , le problème religieux s'aggrava. La guerre de succession d'Autriche opposa de nouveau la France à l'Angleterre. Les Acadiens de la Nouvelle-Écosse, en grande majorité, avaient prêté le serment de fidélité au roi d'Angleterre, avec une restriction de neutralité 
en cas de guerre. Ils y demeuraient fịdèles. Un de leurs missionnaires, l'abbé Jean-Louis Le Loutre, les incità à passer au Nouveau-Brunswick, pour se soustraire à la domination de Londres. Les autorités civiles de la Nouvelle-Écosse s'opposaient au passage des Acadiens en territoire français. Ils demandèrent à l'évêque de Québec d'intervenir, afin que les missionnaires catholiques n'ágissent pas contre les intérêts de leur province. Un sérieux problème de conscience s'est alors posé aux Acadiens dissidents. Ceux de la Nouvelle-Écosse avaient déjà prêté le serment de fidélité au roi d'Angleterre. Passé au Nouveau-Brunswick, qui était encore considéré comme territoire français, ils devaient prêter un nouveau serment de fidélité au roi de France. Manquaient-ils à leur serment envers le roi d'Angleterre ? Les missionnaires ne pouvaient pas donner de solution à ce problème de conscience. Le cas fut référé à l'évêque de Québec, $\mathrm{M}^{\mathrm{gr}}$ Henri-Marie de Pontbriand. Par prudence diplomatique, il ne voulut pas trancher la question. Cependant, l'abbé de l'Islc-Dicu, vicaire général de Québec, mais résidant à Paris, conseilla à l'abbé Le Loutre de juger les cas selon les circonstances. Cette situation ambigüe continua jusqu'à la dispersion des Acadiens, en 1755.

\section{DISPERSION DES ACADIENS AU NOUVEAU-BRUNSWICK $1755-1763$}

Avec la dispersion des Acadiens se termine pour les catholiques du Nouveau-Brunswick la période de liberté relative dont ils jouissaient depuis le traité d'Utretch de 1713. En 1755, il y avait environ 3,000 Acadiens au Nouveau-Brunswick, et autant d'Indiens. Cinq missionnaires étaient à leur service : l'abbé Jean-Louis Le Loutre, l'abbé François Leguerne, et le Père de la Brosse, s.j., dans le sud ; l'abbé Manach dans la région de la Miramichi ; le Père Charles Germain, s.j., à la rivière Saint-Jean.

La dispersion des Acadiens a commencé au sud du NouveauBrunswick, en 1755, avec la prise du Fort Beauséjour par les troupes du général Monckton. Les habitants furent dispersés, les églises brûlées. Les quelques missions catholiques de la rivière Saint-Jean échappèrent cependant à la tourmente. Le 26 juillet 1758, Louisbourg, au Cap-Breton, capitula devant les forces anglaises. Le 26 août suivant, Jeffrey Amherst qui commandait les forces contre Louisbourg, envoya un ordre au général Monckton de se rendre de Halifax à la rivière Saint-Jean, pour y déloger les Français qui s'y trouvaient encore. Les dernières missions du Nouveau-Brunswick furent anéanties en 1759. Mais déjà en 1758, la Nouvelle-Écosse s'était dotée d'un Conseil législatif. Le territoire du Nouveau-Brunswick avait été officiellement 
incorporé à cette province. Les quelques catholiques qui demeuraient dans le territoire du Nouveau-Brunswick passaient définitivement sous le régime anglais et perdaient leurs libertés religieuses, selon les normes des lois de Londres.

Si jamais il demeurait encore quelques doutes au sujet de l'appartenance du Nouveau-Brunswick à l'Angleterre, ils furent dissipés par le traité de Paris. Ce traité signé en 1763, en plus de céder la province de Québec à l'Angleterre. spécifiait que toute l'Acadie était concédée à l'Angleterre. Et le territoire du Nouveau-Brunswick y était compris.

Le traité de Paris, comme celui d'Utretch d'ailleurs, accordait bien la liberté religieuse aux catholiques, mais avec une clause restrictive : «En autant que le permettent les lois de la Grande-Bretagne ». Les lois d'Angleterre d'alors toléraient l'exercice de la religion catholique dans les colonies du royaume, mais n'admettaient pas la présence d'évêques catholiques. Pour évaluer le lent cheminement de l'Église catholique au Nouveau-Brunswick, il faut reconnaître qu'après le traité de Paris, en 1763, les catholiques de la province de Québec ont bénéficié de l'Acte de Québec de 1774, alors que ceux du Nouveau-Brunswick en furent privés. Cet acte soustrayait les libertés religieuses du Québec de la juridiction " des lois de la Grande-Bretagne ", pour les placer sous " la suprématie du roi ». Le roi, étant l'autorité suprême, pouvait accorder certaines exemptions aux lois antireligieuses de la GrandeBretagne. De plus, l'Acte de Québec remplaçait le serment du Test par une formule acceptable aux catholiques qui désiraient accéder aux charges publiques. Mais cet Acte de Québec ne s'appliquait pas au Nouveau-Brunswick.

En 1758, avec la constitution du premier Conseil législatif de Halifax, le territoire du Nouveau-Brunswick passa sous la juridiction civile de la Nouvelle-Écosse. Étant ainsi placé sous la domination de l'Angleterre, qui ne reconnaissait pas la juridiction du Pape, le NouveauBrunswick passait sous l'autorité de la Congrégation de la Propagande.

Après la dispersion, les catholiques du Nouveau-Brunswick, soit indigènes, soit acadiens, demeurèrent sans prêtres pendant cinq ou six ans. Mais ils gardèrent fidèlement leurs pratiques religieuses. Les laïcs devinrent les responsables de leurs communautés chrétiennes. L'évêque de Québec leur permettait d'avoir « la messe blanche ». Dans chaque localité, des personnes étaient désignées pour baptiser, présider aux funérailles, recevoir les consentements de mariage, et même dispenser de certains empêchements. Certains de ces laïcs étaient désignés officiellement par l'évêque de Québec, pour remplir ces " ministères ". 
Graduellement les missionnaires revinrent auprès des catholiques du Nouveau-Brunswick. En 1768, ce fut l'abbé François Bailly, futur coadjuteur de Québec. Il fut suivi en 1770 du Père Jean-Baptiste de La Brosse, s.j. En 1774, l'évêque de Québec, $\mathrm{M}^{\mathrm{gr}}$ Jean-Olivier Briand, nomma l'abbé Mathurin Bourg vicaire général du Nouveau-Brunswick et de toute l'Acadie. Il s'installa à Carleton, en Gaspésie. Il lui fallait une permission du gouverneur de Halifax pour exercer son ministère au Nouveau-Brunswick. Mais il ne semble pas y avoir eu de problèmes à ce sujet. En 1778, l'évêque de Québec, à la demande du gouverneur de Halifax, nomma l'abbé Bourg missionnaire auprès des Indiens du Nouveau-Brunswick et de la Nouvelle-Écosse, afin qu'il intervienne auprès d'eux dans le but de les empêcher de s'allier aux Américains dans la guerre d'Indépendance. Il exerça ses fonctions de vicaire général au Nouveau-Brunswick jusqu'en 1795.

Avec le cours des années, le gouvernement de Londres abrogea ses lois anticatholiques. Le 3 juin 1778, quatre ans après l'Acte de Québec, il adopta The Catholic Relief Act. Cet Acte permettait aux catholiques de construire des églises, d'avoir des services religieux et d'avoir des prêtres. Les prêtres cependant devaient obtenir une permission du gouverneur et prêter un serment acceptable à leur conscience. Le 2 décembre 1783, à la demande des catholiques de la Nouvelle-Écosse, le gouvernement de Halifax approuva un Acte pour l'adoption du Catholic Relief Act. La requête fut ratifiée par le roi d'Angleterre le 2 juillet 1784. Cependant, la défense d'avoir des évêques catholiques n'avait pas été révoquée.

Le 22 novembre 1784, le Nouveau-Brunswick fut officiellement détaché de la Nouvelle-Écosse et proclamé province. Les catholiques de cette nouvelle province pouvaicnt bénéficier des concessions de libertés religieuses accordées à ceux de la Nouvelle-Écosse par le roi d'Angleterre, le 2 juillet précédent. Avec le concours de prêtres venus de Québec et de France, la vie religieuse s'organisa graduellement. Mais l'arrivée des Loyalistes à cette époque s'avérait un danger pour la renaissance des catholiques. Pour se protéger, ils se groupèrent en villages isolés, soit au Madawaska, à la Baie des Chaleurs, ou dans la région de Memramcook et Richibouctou. Ils ont ainsi résisté à l'assimilation ouvertement voulue par le colonialisme anglais. Ils demeuraient toujours sous la juridiction religieuse de l'évêque de Québec, qui les visitait occasionnellement. 


\section{LE NOUVEAU-BRUNSWICK SOUS LA JURIDICTION DE CHARLOTTETOWN, 1821}

Selon les clauses du traité de Paris (1763), Rome ne pouvait pas ériger de nouveaux diocèses au Canada, et pas plus au NouveauBrunswick. L'évêque de Québec reconnaissait qu'il ne pouvait pas adéquatement desservir l'immense territoire qui lui avait été assigné. En 1796, il signifia à Rome que son diocèse devrait être divisé et placé sous la juridiction d'évêques coadjuteurs. En 1806, Mr Joseph-Octave Plessis insista pour que le Nouveau-Brunswick, la Nouvelle-Ėcosse et l'Ile-duPrince-Édouard, soient placés sous la juridiction d'un coadjuteur. En 1817, il demanda à la Propagande d'ériger le Nouveau-Brunswick en vicariat apostolique. Mais toujours sans succès, surtout parce que Londres s'opposait au projet. En 1819, Londres, devenant de plus en plus conciliant envers les catholiques, mais ne voulant pas approuver en principe la nomination de nouveaux évêques au Canada, accorda des évêques auxiliaires à l'évêque de Québec. C'est ainsi que le 12 janvier 1819 , avec l'approbation de Londres, Angus Bernard MacAechern, prêtre de l'Ile-du-Prince-Édouard, fut nommé évêque auxiliaire suffragant du Nouveau-Brunswick, de l'Ile-du-Prince-Édouard, et des Iles-de-laMadeleine.

Le titre assigné à $\mathrm{M}^{\mathrm{rr}} \mathrm{MacAechern} \mathrm{était} \mathrm{assez} \mathrm{inusité.} \mathrm{Il} \mathrm{était} \mathrm{nommé}$ auxiliaire suffragant. Un évêque auxiliaire est habituellement nommé dans un diocèse qui a déjà un évêque résident. Un suffragant est un évêque de plein droit, dont le diocèse fait partie d'une province ecclésiastique, avec un archevêque comme métropolitain. Ce n'était pas le cas pour $\mathrm{M}^{\mathrm{r} r}$ MacAechern! De plus, un évêque auxiliaire n'a pas de territoire propre. Mais les bulles de nomination de $\mathrm{M}^{\mathrm{gr}}$ MacAechern lui assignaient comme territoire le Nouveau-Brunswick, l'Ile-du-PrinceÉdouard et les Iles-de-la-Madeleine, sous la juridiction de l'évêque de Québec. C'était un ménagement diplomatique aux exigences de Londres que Rome concédait ainsi. Mr MacAechern fut ordonné évêque le 17 juin 1821. Par un mandement du 15 octobre suivant, Mgr J.-O. Plessis, évêque de Québec, lui transféra la juridiction assignée par ses bulles de nomination. Il n'est pas fait mention de juridiction de vicaire général dans ce mandement.

Le Nouveau-Brunswick passait ainsi sous l'autorité religieuse de ce nouvel évêque auxiliaire suffragant de Québec. Les catholiques de cette province ont bénéficié du ministère épiscopal de $\mathrm{M}^{\mathrm{gr}}$ MacAechern avant ceux de l'Ile-du-Prince-Édouard, où il devait élire domicile. En revenant de Québec, après son ordination épiscopale, il s'arrêta au NouveauBrunswick pendant deux semaines et il y visita plusieurs missions. 
$M^{\mathrm{gr}}$ MacAechern demeurait sous la juridiction de l'évêque de Québec. Cette dépendance, ajoutée aux grandes distances à parcourir, rendait l'administration de l'évêque de Charlottetown assez difficile. En 1825, il demanda à Rome de détacher son territoire de celui de Québec et de le constituer en diocèse séparé. La requête ne fut pas approuvée. En 1826, il présenta de nouveau sa requête. Cette fois, Londres semblait favorable à sa demande, mais Rome ne jugea pas opportun d'accéder à cette requête.

\section{LE NOUVEAU-BRUNSWICK ET LE DIOCÈSE DE CHARLOTTETOWN 1829}

Le 13 avril 1829, Londres adopta " An Act for the Relief of $\mathrm{His}$ Majesty's Roman Catholic subjects ». À la suite de cet acte d'émancipation, le gouvernement de l'Angleterre ne s'opposait plus officiellement à la nomination de nouveaux évêques au Canada. Il se réservait cependant le droit d'approbation. Avec la permission de Londres, le 10 août 1829, Rome érigea le diocèse de Charlottetown. $\mathrm{M}^{\mathrm{gr}}$ MacAechern en fut nommé le premier évêque. Charlottetown devenait en même temps le premier diocèse catholique érigé au Canada après l'Acte d'émancipation de 1829. L'Acte d'émancipation fut approuvé par le gouvernement du Nouveau-Brunswick le 8 mars 1830 . M $^{\mathrm{gr}}$ MacAechern fut installé évêque de Charlottetown le 11 novembre 1830. Ainsi les catholiques du Nouveau-Brunswick passaient sous la juridiction de l'évêque résidentiel de Charlottetown et jouissaient des libertés religieuses que leur accordait Londres.

Une des grandes préoccupations pastorales de $\mathrm{M}^{\mathrm{gr}}$ MacAechern fut le recrutement sacerdotal. Immédiatement après son installation comme évêque, il communiqua avec l'évêque catholique de Londres, pour obtenir les services de quelques prêtres français réfugiés en ce pays. Mais aucun d'entre eux n'accepta. Il avait aussi le projet d'un collège à Saint Andrew's, à l'Ile-du-Prince-Édouard. En juillet 1831, il fit une visite au Nouveau-Brunswick, dans le but de renseigner la population catholique au sujet de ce collège. À l'automne de la même année, il revint à la rivière Saint-Jean et passa l'hiver dans la province. Il constata que les catholiques du Nouveau-Brunswick n'étaient pas disposés à contribuer financièrement au collège Saint Andrew's. Cependant, il réussit à obtenir du gouvernement de la province la somme de 100 livres, pour la construction d'une école qu'il se proposait d'ouvrir à Shédiac.

$\mathrm{M}^{\mathrm{gr}}$ MacAechem avait au moins deux vicaires généraux au NouveauBrunswick. Il avait accordé les facultés de vicaire général à l'évêque de Québec, qui s'en servait surtout dans la région du Madawaska. Le 6 
avril 1835, il nomma le Père Antoine Gagnon vicaire général, surtout pour le secteur sud du Nouveau-Brunswick.

$M^{\text {gr }}$ MacAechern avait constaté que le territoire qu'il avait à desservir était beaucoup trop étendu. Le 21 mars 1835, un mois avant son décès, il avait fait part à l'évêque de Québec de son intention de demander un coadjuteur. Il avait même pensé que Saint-Jean, au Nouveau-Brunswick, pourrait devenir le lieu de résidence de ce nouvel évêque. Mais. l'évêque de Charlottetown était décédé avant de voir la réalisation de son projet.

À la suite de son décès, survenu le 22 avril 1835. les catholiques du Nouveau-Brunswick restèrent sans évêque pendant plus de deux ans. Durant la vacance du siège épiscopal, le diocèse fut administré par le Père Donald MacDonald, ancien vicaire général. Celui-ci fut nommé évêque de Charlottetown en 1836 et ordonné le 15 octobre 1837. Le Nouveau-Brunswick demeura sous sa juridiction pendant cinq ans.

\section{DIOCĖSE DU NOUVEAU-BRUNSWICK, 1842}

Le 30 septembre 1842, le Nouveau-Brunswick fut détaché de Charlottetown et érigé en diocèse. Il portait le titre de diocèse du NouveauBrunswick. $\mathbf{M}^{\mathrm{gr}}$ William Dollard, premier titulaire, fut ordonné le 11 juin 1843. Il avait été nommé évêque avec l'approbation de Londres, selon les exigences de l'Acte de 1829. Comme $\mathbf{M}^{\mathrm{gr}}$ Dollard était curé à Fredericton lors de sa nomination, il établit sa résidence en cette ville. Il y avait alors treize prêtres dans le nouveau diocèse.

Le 12 juillet 1844, le diocèse du Nouveau-Brunswick est devenu suffragant du siège métropolitain de Québec. Lorsque l'évêque de Québec fut promu au rang d'archevêque, Londres ne lui permettait pas de porter le titre de métropolitain. Ce n'est que plus tard qu'il fut autorisé à se servir de son titre officiel.

Le 6 juillet 1846, le diocèse fut civilement incorporé sous le titre légal de poman Catholic Bishop of New Brunswick. Le droit ecclésiastique français, reconnu par l'Acte de Québec de 1774, ne s'appliquait pas an Nouveau-Brunswick. Officiellement le système des fabriques et des rvarguilliers, encore en vigueur au Québec, disparaissait au NouveauBrinswick, par l'acte d'incorporation du diocèse en 1846.

$\mathrm{M}^{\mathrm{gr}}$ Dollard transféra son siège épiscopal à Saint-Jean et éventuellement le diocèse prit le titre de diocèse de Saint-Jean, Nouveau-Brunswick. Le premier évêque résidentiel du Nouveau-Brunswick mourut le 20 août 
1851 et fut remplacé par $\mathrm{M}^{\mathrm{gr}}$ Thomas Louis Connolly, un capucin, le 15 août 1852. Le 4 mai 1852 , le diocèse de Saint-Jean était devenu suffragant de la nouvelle province ecclésiastique de Halifax, NouvelleÉcosse, avec $\mathbf{M}^{\mathrm{g} r}$ William Walsh comme premier métropolitain. $\mathbf{M}^{\mathrm{gr}}$ Connolly, deuxième évêque de Saint-Jean, fut transféré au siège de Halifax, le 15 avril 1859. Il fut remplacé à Saint-Jean, par M ${ }^{\mathrm{gr}} \mathrm{John}$ Sweeney, qui fut élu le 29 novembre 1859 et ordonné le 15 avril 1860.

\section{DEUX DIOCÈSES AU NOUVEAU-BRUNSWICK, 1860}

La possibilité de diviser le Nouveau-Brunswick en deux diocèses avait été étudiée dès avant 1850 . Le siège épiscopal de Saint-Jean n'était pas géographiquement central, étant à l'extrémité sud de la province. $\mathrm{M}^{\mathrm{gr}}$ Dollard étudia ce projet avec $\mathrm{M}^{\mathrm{z}}$ Walsh, alors évêque à Halifax. Il prévoyait la possibilité d'avoir un évêque de langue française pour les catholiques du nord de la province. $\mathrm{M}^{\mathrm{r}} \mathrm{W}$ Walsh semblait favorable à cette division. Il se demande cependant s'il ne serait pas préférable d'avoir un évêque coadjuteur pour le diocèse de Saint-Jean. Ni l'un ni l'autre de ces projets ne fut réalisé. Le démembrement du diocèse de SaintJean se fera attendre pendant encore 10 ans.

Le 6 mai 1860, la partie nord du Nouveau-Brunswick fut détachée du diocèse de Saint-Jean, et érigée en diocèse, avec siège épiscopal à Chatham, dans le comté de Northumberland. Le même jour, $\mathrm{M}^{\mathrm{gr}} \mathrm{James}$ Rogers en fut désigné le premier évêque. Cette nomination fut faite sans l'intervention de Londres, alors que 18 ans auparavant, celle de $\mathrm{M}^{\mathrm{gr}}$ Dollard, évêque de Saint-Jean, portait l'approbation du gouvernement anglais. Le Nouveau-Brunswick comptait alors une population totale de 252,000 citoyens, dont 85,000 appartenaient à la religion catholique, soit $30 \%$. Le nouveau diocèse de Chatham comptait 45,000 fidèles, alors que celui de Saint-Jean en comptait 40,000.

Lorsque la requête fut adressée à Rome pour obtenir l'érection du diocèse du Nouveau-Brunswick (devenu diocèse de Saint-Jean, N.-B.), les conflits des frontières entre le Madawaska américain et le Madawaska néo-brunswickois n’étaient pas encore réglés. Mais, 39 jours avant l'émission de la bulle d'érection du nouveau diocèse. le traité d'Ashburton céda la partie sud de la rivière Saint-Jean aux États-Unis. Rome n'était évidemment pas encore au courant de cette division territoriale lorsque, le 30 septembre 1842 , elle érigera le diocèse du Nouveau-Brunswick, comprenant le Madawaska américain. L'évêque de Saint-Jean avait donc juridiction au Madawaska américain. De 1842 à 1852, il confia l'administration du Madawaska, des deux 
côtés de la rivière Saint-Jean, à l'évêque de Québec, pour des raisons de facilités de communications.

Mais, en 1860, lorsque le diocèse de Chatham fut fondé. le Madawaska américain ne lui fut pas annexé. Il resta sous la juridiction de l'évêque de Saint-Jean. Comme le Madawaska américain devenait limitrophe de diocèse de Chatham, $\mathbf{M}^{\mathrm{gr}}$ Rogers, l'année même de sa nomination comme évêque de Chatham, fit rapport à Rome de cette situation Rome laissa le Madawaska américain sous la juridiction de l'évêque de Saint-Jean. N.-B., mais nomma l'évêque de Chatham administrateur du territoire américain. Cette situation dura pendant 10 ans. En 1870, le Madawaska américain fut annexé au diocèse de Portland, Maine.

Même après l'érection d'un deuxième diocèse au Nouveau-Brunswick. les évêques avaient encore de grands territoires à desservir. Lcurs préoccupations majeures semblaient être le recrutement sacerdotal et l'éducation de la jeunesse. Ces deux problèmes se sont accentués avec l'adhésion de la province à la confédération canadienne.

Les deux évêques du Nouveau-Brunswick, $\mathrm{M}^{\mathrm{g} r}$ Sweeney et $\mathrm{M}^{\mathrm{r}}$ Rogers, étaient en principe favorables à la confédération canadienne. Leur appui à ce projet avait même été sollicité par $\mathbf{M}^{\mathrm{gr}} \mathrm{C}$.-F. Baillargeon, alors administrateur de Québec. Mais les deux évêques demandaient que l'Acte de l'Amérique du Nord Britannique place l'instruction publique sous la juridiction du gouvernement fédéral, et que le droit des écoles confessionnelles soit enchâssé dans l'Acte. Les évêques de Québec, pour leur part, jugeaient que les droits des écoles confessionnelles seraient mieux protégés si l'instruction publique demeurait sous la juridiction de chaque province. Au Québec, les écoles paroissiales jouissaient déjà d'un statut officiel depuis 1824 , alors qu'au NouveauBrunswick, les écoles paroissiales existaient, mais n'avaient pas de statut légal. En définitive, l'article 93 de l'Acte de l'Amérique du Nord Britannique accorda aux provinces toute juridiction dans le domaine scolaire, et les écoles paroissiales n'ont jamais été reconnues officiellement par le Nouveau-Brunswick.

En 1871, les catholiques du Nouveau-Brunswick ressentirent les effets adverses de la loi scolaire telle que préconisée par la Constitution fédérale de 1867. Le gouvernement provincial tit adopter la loi du "Common School Act ». Par cette législation, seules les écoles publiques pouvaient bénéficier des subsides en provenance des taxes des citoyens. C'était une atteinte à l'existence des écoles paroissiales catho- 
liques. Des contestations surgirent de tous les groupes catholiques. Un appel fut fait au Conseil Privé à Londres. Sa décision ne servit qu'à confirmer la loi de 1871. Mais les catholiques, aux prix de grands sacrifices, et avec l'aide des communautés religieuses, continuèrent à maintenir presque partout leurs écoles paroissiales.

\section{PROVINCE ECCLÉSIASTIQUE AU NOUVEAU-BRUNSWICK, 1936}

En 1936, l'Église catholique au Nouveau-Brunswick a atteint ce qui pourrait être appelé sa maturité hiérarchique. Le 22 février de cette année, l'archidiocèse de Moncton fut érigé par un démembrement des diocèses de Saint-Jean et de Chatham. Moncton devenait le siège métropolitain de la nouvelle province ecclésiastique. Les trois diocèses comptaient alors une population catholique d'environ 200,000 fidèles. Le premier archevêque fut $\mathbf{M}^{\mathrm{r}} \mathbf{L}$.-J.-Arthur Melanson, transféré du diocèse de Gravelbourg, en Saskatchewan, où il était évêque depuis 1933. Il fut intronisé en la cathédrale l'Assomption, à Moncton, le 22 février 1937.

Le projet de ce troisième diocèse au Nouveau-Brunswick n'était pas nouveau. Dès le début de son épiscopat, M ${ }^{\mathrm{gr}}$ Rogers, évêque de Chatham, avait désigné Bathurst comme siège éventuel d'un évêché. Vers 1907, la possibilité d'ériger ce troisième diocèse fut sérieusement étudiée par $\mathrm{M}^{\mathrm{gr}}$ Thomas Barry, successeur de $\mathrm{M}^{\mathrm{gr}}$ Rogers. Il demandait que le nord de la province du Nouveau-Brunswick soit érigé en diocèse, avec siège épiscopal à Bathurst. Mais les catholiques des comtés de Kent et de Westmorland demandaient également que Moncton devienne siège épiscopal. Rome différa sa décision jusqu'en 1936, alors que Moncton fut désigné comme siège métropolitain de la province du Nouveau-Brunswick. Le 13 mai 1938, le siège épiscopal de Chatham fut transféré à Bathurst, mais les frontières interdiocésaines ne furent pas modifiées.

Le 16 décembre 1944, la province ecclésiastique du Nouveau-Brunswick s'est enrichie d'un quatrième diocèse, celui d'Edmundston, comprenant les comtés de Madawaska, Victoria, et la partie ouest de Restigouche. Ce nouveau diocèse est formé d'un démembrement de celui de Bathurst. Le premier titulaire fut $\mathrm{M}^{\mathrm{gr}}$ Marie-Antoine Roy, franciscain, ordonné en sa cathédrale le 15 août 1945 . Le nouveau diocèse comptait 24 paroisses.

La dernière modification de frontières interdiocésaines s'est effectuée en 1959. Le 9 février de cette année, le secteur de la Miramichi, situé dans le comté de Northumberland, a été détaché du diocèse de Bathurst pour être annexé à celui de Saint-Jean. Quinze paroisses ont été transférées par ce changement. 
En 1981, un autre chapitre s'ajoute à l'histoire de l'Église au Nouveau-Brunswick. Le 8 août. Mer Arthur Gilbert, évêque de Saint-Jean, a fondé deux paroisses pour des catholiques francophones de son diocèse : une en la ville de Saint-Jean, et l'autre à Fredericton. Un élément ecclésial intéressant à noter est le fait que, par le décret de fondation. Mgr Gilbert autorise les curés de ces deux nouvelles paroisses à administrer les sacrements dans les autres paroisses de ces deux villes, avec l'autorisation de leur curé respectif. Le canon 216 de l'ancien Code de droit canonique était plutôt restrictif au sujet des paroisses nationales. L'évêque de Saint-Jean s'est inspiré de l'esprit de Vatican II, qui préconise "une méthode plus appropriée " lorsqu'il s'agit de pourvoir au bien spirituel des groupes linguistiques minoritaires.

Edgar GoDIN

Évêque de Bathurst, N.-B. 


\section{ÉVÊQUES DU NOUVEAU-BRUNSWICK}

Archidiocèse de Moncton

$\mathrm{M}^{\mathrm{gr}}$ L.-J.-Arthur Melanson

1937-1941

M"r Norbert Robichaud

1941-1972

Mgr Donat Chiasson

1972

Diocèse de Saint-Jean

Mgr William Dollard

1842-1852

Mer Thomas L. Connolly

1852-1859

M"r John Sweeney

1860-1901

Mer Timothy Casey

1901-1912

$M^{g}{ }^{2}$ Edouard-A. LeBlanc

1912-1935

$\mathrm{M}^{\mathrm{gr}}$ Patrick A. Bray, C.J.M.

1936-1953

$\mathrm{M}^{\mathrm{gr}}$ Alfred B. Leverman

1953-1968

Mgr Joseph MacNeil

1969-1974

$\mathrm{Mgr}^{\mathrm{gr}}$ Arthur Gilbert

1974

Diocèse de Bathurst (Chatham)

Mgr James Rogers

1860-1902

Mer Thomas F. Barry

1902-1920

MEr Patrice-A. Chiasson, C.J.M.

1920-1942

Mer Camille-André LeBlanc

1942-1969

Mgr Edgar Godin

1969

Diocèse d'Edmunston

Mgr Marie-Antoine Roy, O.F.M.

1945-1948

Mrr J.-Roméo Gagnon

1949-1970

Mgr Fernand Lacroix, C.J.M.

1970

\section{SOURCES}

Archives provinciales du Nouveau-Brunswick, Fredericton, N.-B.

Archives provinciales de la Nouvelle-Écosse, Halifax, N.-S.

Archives nationales du Canada, Ottawa.

Archives diocésaines, Bathurst, N.-B.

Archives diocésaines, Québec.

Archives diocésaines, Charlottetown, I.P.E.

Centre des études acadiennes, Université de Moncton, Moncton, N.-B. 


\section{BIBLIOGRAPHIE}

AI.BERT, Thomas, Histoire du Madawaska, 1920.

BERNARD, Frère Antoine, Histoire de l'Acadie. 1939.

Campeal. Lucien, s.j.. L'Évêché de Québec (1674), 1974.

CANDIDE de Nant, o.f.m. cap., Pages glorieuses de l'épopée canadienne', 1927.

Chapals, Thomas, Cours d'histoire du Canada, 1919-1934

D'entremont. Clarence-J.. Histoire du Cap Sable, 1938.

Dominique de Saint-Denis. o.f.m. cap.. L'Église catholique au Canada. 1956.

Groulx. Lionel. Histoire du Canada français, 1960.

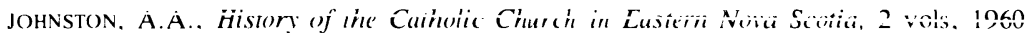
et 1971 .

Jouve. Odoric-Marie. o.f.m.. Les Franciscains et le Canada, 1915.

MaC Mil.Lan, John C.. History of the Catholic Church in Prince Edward Island, 1913.

MacNutt, W.S.. The Atlantic Provinces, 1965.

PACIFIQUE de Valigny. o.f.m. cap.. Chroniques des plus anciennes églises de l'Acadie. 1944.

Pineal, Wilfrid, Le clergé français dans l'Ile du Prince-Édouard, 1967.

RAYMOND, W.O.. History of the River St. John, 1905.

SAvole, Alexandre-J., Un siècle de revendications scolaires au Noureau-Brunswick. 1978.

Diocese of Charlottetown, 1829-1979.

The Catholic Church in Prince Edward Island.

Relations des Jésuites. 